\title{
Vaccination coverage in Lebanon following the Syrian crisis: results from the district- based immunization coverage evaluation survey 2016
}

Ziad Mansour ${ }^{1}$, Randa Hamadeh², Alissar Rady ${ }^{3}$, M. Carolina Danovaro-Holliday ${ }^{4}$, Kamal Fahmy ${ }^{5}$, Racha Said ${ }^{1 *}$ (D, Lina Brandt ${ }^{1}$, Ramy Warrak ${ }^{1}$ and Walid Ammar $^{2}$

\begin{abstract}
Background: Following the Syrian crisis, a substantial influx of Syrian refugees into Lebanon posed new challenges to optimal vaccination coverage for all children residing in the country. In 2016, the district-based immunization coverage evaluation survey (CES) assessed routine immunization coverage at the district level in Lebanon among children aged 12-59 months.

Methods: A cross-sectional multistage cluster survey was conducted in all of Lebanon (with the exception of the Nabatieh district) using the World Health Organization (WHO) recommended Expanded Programme on Immunization (EPI) methodology adapted to the local context. A survey questionnaire consisting of closed and open-ended questions concerning demographic information and the child's immunization status was administered to collect immunization status information.

Results: Among surveyed children aged 12-59 months, irrespective of nationality, vaccination coverage at the national level for any recommended last dose was below the targeted $95 \%$. Generally, vaccination coverage levels increased with age and were higher among Lebanese than Syrian children. However, large variations were revealed when coverage rates were analyzed at the district level. Vaccination was significantly associated with nationality, age, mother's educational status and the place of vaccination. Common reasons for undervaccination included the child's illness at the time of vaccine administration, vaccination fees, lack of awareness or a doctor's advice not to vaccinate during campaigns.

Conclusions: Substantial variability exists in vaccination coverage among children aged 12-59 months residing in different districts in Lebanon. Immunization coverage reached $90 \%$ or above only for the first doses of polio and pentavalent vaccines. A considerable dropout rate from the first dose of any vaccine is observed. Efforts to optimize coverage levels should include increased vaccination initiatives targeting both refugee children and children from vulnerable host communities, increased cooperation between public and private vaccine providers, improved training for vaccine providers to adhere to complete vaccine administration recommendations, and increased awareness among caregivers.
\end{abstract}

Keywords: Expanded Programme on immunization, Vaccination coverage, Coverage evaluation survey, Lebanon, Syrian refugees

\footnotetext{
* Correspondence: saidr@crdconsultancy.org

${ }^{1}$ Connecting Research to Development, Beirut, Lebanon

Full list of author information is available at the end of the article
}

(c) The Author(s). 2019 Open Access This article is distributed under the terms of the Creative Commons Attribution 4.0 International License (http://creativecommons.org/licenses/by/4.0/), which permits unrestricted use, distribution, and reproduction in any medium, provided you give appropriate credit to the original author(s) and the source, provide a link to the Creative Commons license, and indicate if changes were made. The Creative Commons Public Domain Dedication waiver (http://creativecommons.org/publicdomain/zero/1.0/) applies to the data made available in this article, unless otherwise stated. 


\section{Background}

Established in 1987 in Lebanon, the Expanded Programme on Immunization (EPI) works toward inclusive vaccination coverage for all children [1]. Table 1 presents the national immunization schedule for children aged 0-59 months adopted by the Lebanese Ministry of Public Health (MoPH) in 2016 [2]. Routine immunization for children in Lebanon is provided by public and private entities, including more than 700 primary healthcare centers and dispensaries [3]. National coverage estimates suggest that generally more than $90 \%$ of children are being reached with mandatory vaccines [4]. Nevertheless, an outbreak of measles in 2013 and a strong increase in cases of mumps in 2015 indicate the vulnerability of the current Lebanese vaccination coverage system [5].

The enormous influx of Syrian refugees into the country since 2011 has posed challenges to optimal provision of immunization services and access to quality immunization services [5]. Due to the disrupted provision of vaccines in Syria as well as the difficulty in accessing to healthcare services by refugees, many Syrian children lack optimal immunization coverage [6]. The Vulnerability Assessment of Syrian Refugees in Lebanon confirms incomplete vaccination coverage among $50 \%$ of all surveyed Syrian children [7]. Another vaccination coverage cluster survey in the North of Lebanon in 2015 identifies a decisively lower vaccination coverage level

Table 1 Routine vaccination schedule for children aged 0-59 months in Lebanon [2]

\begin{tabular}{lll}
\hline Child's age & Vaccine & Doses \\
\hline at birth & HepB & Zero Dose \\
2 months & IPV & 1st Dose \\
& Penta (DTP, Hib and HepB) & 2nd Dose \\
4 months & OPV & \\
6 months & Penta (DTP, Hib, HepB) & 3rd Dose \\
9 months & OPV & Zero Dose \\
12 months & Penta (DTP, Hib, HepB) & 1st Dose \\
18 months & Measles vaccine ${ }^{\text {a }}$ & 1st Booster \\
& MMR ${ }^{a}$ & \\
OPV & Penta (DTP, Hib, HepB) & 2nd Dose \\
& MMR & 2nd Booster \\
& OPV & \\
& DTP &
\end{tabular}

HepB Hepatitis B, Hib Haemophilus influenzae type b, IPV Inactivated Polio Vaccine, DTP Diphtheria, Tetanus, Pertussis, OPV Oral Polio Vaccine, MMR Measles, Mumps, Rubella

${ }^{\mathrm{a}}$ In this article, measles and MMR vaccines were entered as measles-containing vaccine (MCV) (either measles or MMR vaccines) and rubella-containing vaccine $(R C V)$ among Syrian children compared to children from host communities [8].

In this regard, the EPI program in Lebanon aims at " 1 ) elevating routine vaccination coverage in every district to above $95 \%, 2)$ preserving Lebanon as polio-free [...], and 3) eradicating measles and rubella by the end of year 2018" [1]. Scale-up routine immunization and vaccination campaigns are used to respond to the increased risk of disease outbreaks. Regular monitoring and coverage estimation permit the evaluation of these vaccination efforts. To assess routine immunization coverage at the district level in Lebanon, a coverage evaluation survey (CES) was conducted among children aged 12-59 months between December 2015 and June 2016 [9]. The resulting evidence helps provide a better understanding of the current status and determinants of immunization uptake in Lebanon and aims to inform relevant stakeholders about achievements and shortcomings of their attainments.

\section{Methods}

A cross-sectional survey was conducted between December 2015 and June 2016 among caregivers of children aged 12-59 months in all of Lebanon except the district of Nabatieh and was designed to provide district-based vaccine coverage estimates [9].

\section{Sampling}

The study sample included resident children in Lebanon, irrespective of their nationality. Sample size calculations were made at the district level, assuming a conservative vaccination coverage of $50 \%$, a desired precision of $\pm 5 \%$, a probability of achieving that precision of 0.95 and a design effect of 2 . This led to a required sample of 390 children per district, that is, a total sample of 10,140 children from 26 districts.

Following the World Health Organization (WHO) cluster evaluation survey methodology, 26 clusters were randomly selected in each district proportionally to the population estimates obtained from the Central Administration of Statistics, which are based on a population census of 2009, and the United Nations High Commissioner for Refugees [10-12]. The clusters that were likely to be sampled more than once were assigned a fixed number of starting points based on how often they would be selected with certainty. Fifteen children were recruited from each cluster, with each child being selected from a different household.

Households were identified by randomly selecting a landmark from a list of landmarks in each cluster identified prior to the study with the support of local authorities. From the selected landmark, a direction was chosen by spinning a pen or another sharp object to approach the first household. Subsequent households were 
visited according to proximity, selecting the nearest household to continue data collection. If the end of a street was reached, the neighboring street was chosen following a clockwise approach. Participants were recruited until the total number of 15 was reached within each cluster. In the event that more than one eligible child was found in the same household, each child's name was written on a slip of paper and the participating child was chosen at random. If the parent or legal guardian was absent during the field visit, the household was revisited at least twice. The same applied to empty houses where fieldworkers were able to inquire from neighbors that an eligible child should be hosted. Facility traceback to find documented evidence of vaccination was piloted and was found not to be feasible.

\section{Data collection}

Sixty data collectors worked on the ground to collect data throughout the districts. All fieldworkers underwent intensive training on field practices, interview techniques and ethical considerations, as well as pilot test activity. A survey questionnaire (Additional file 1) consisting of closed and open-ended questions about demographic information and the child's immunization status was developed, reviewed and approved by the MoPH, the Lebanon country office of the WHO and the United Nations Children's Fund (UNICEF). The tool was forward- and back-translated from English to Arabic in order to ensure consistency and pilot tested in the cadasters of Dekweneh and Nabaa in Lebanon. Data collection was performed using paper questionnaires and the electronic KoBoCollect application on tablets. Epidata software was used to enter any nonelectronically collected information. Pictures of the child's (one or more) immunization card(s) available in the house were also taken. Further, when a child was known to have missed the vaccination, caregivers were asked about reasons why their child had not been vaccinated for each type of vaccine separately.

\section{Data analysis}

A response rate of $94.3 \%$, accounting for all surveyed cases irrespective of their nationality, led to a total of 9560 children; however, for this study, we excluded 245 (2.6\%) children who were not Lebanese or Syrians living in the communities. Data were analyzed using Stata software, version 14. Descriptive analyses were presented as proportions and means with standard deviations where appropriate. National and district level vaccination coverage estimates and 95\% confidence intervals (CI) were calculated based on the Taylor Series Linearization method to retrieve results for the entire sample. National estimates took into account the sampling design (stratum, district and governorate-specific weight).
Vaccination cards were used for validating received vaccinations, and coverage rates of children with a well-documented vaccination card were presented. If the vaccination card was incomplete or missing, the recall of caregivers was considered to assess the child's vaccination status. Dropout rates were calculated as the difference in coverage between the first and third doses for each of the following: polio, DTP, HepB and Hib; the first and second doses for $\mathrm{MCV}$; and the first dose of DTP and first dose of MCV. A multivariable logistic regression analysis of completed vaccination coverage, also accounting for the sampling design, was performed for each vaccine separately. Significance was considered at a $p$-value $<0.05$ following a $\mathrm{t}$-distribution.

\section{Ethical considerations}

Before each interview, oral informed consent was obtained from the child's caretaker. Written consent was not obtained as this is not a common practice for this type of studies in Lebanon, given the low levels of literacy among certain populations and the non-sensitive nature of the information obtained. All participants were informed of their completely free choice of participation and the strict application of confidentiality to any of the participants' disclosed information. Prior to the start of any interview, participants received a brief but thorough explanation of the scope and aim of the survey. The Institutional Review Board at Sagesse University approved the study. Only the study team handled the database and pictures to ensure data confidentiality.

\section{Results}

\section{Survey population}

In total, 9315 Lebanese and Syrian children participated in the survey (Table 2). Included households had a mean size of 5.17 individuals (+SD 2.24) and a mean number of eligible children of 1.59 (+SD 0.88). Among the surveyed children, 7136 (76.6\%) were Lebanese, and 2179 (23.4\%) were Syrian. The sample was almost equally distributed among males and females and among the four age groups. Vaccination cards were presented for 5713 (61.4\%) children, whereas for 3375 (36.2\%) children, vaccination status was assessed through the recall of caregivers. Additionally, 227 children (2.4\%) in the sample never received any vaccination. Enrolled children predominantly lived either in a rented $(47.9 \%)$ or an owned (48.8\%) house. Furthermore, 8559 (91.9\%) of the caregivers were married with a mean age of 30.9 years (+SD 6.7). In addition, 5336 of fathers (57.2\%) and 5089 (54.6\%) of mothers completed at least their secondary level of education. Among fathers, approximately two-thirds (66.3\%) had a full-time job compared to one-third of mothers (30.2\%). Table 3 presents key sociodemographic factors by nationality. 
Table 2 Household distribution by governorate/district (unweighted), Lebanon CES 2016

\begin{tabular}{|c|c|c|c|c|c|c|c|c|}
\hline \multirow{3}{*}{$\begin{array}{l}\text { Governorate } \\
\text { District }\end{array}$} & \multirow{2}{*}{\multicolumn{2}{|c|}{ Total }} & \multirow{2}{*}{\multicolumn{2}{|c|}{ Lebanese }} & \multicolumn{4}{|c|}{ Household characteristics } \\
\hline & & & & & \multicolumn{2}{|c|}{ Syrian } & \multirow{2}{*}{$\begin{array}{l}\text { Household size } \\
\text { Mean + SD }\end{array}$} & \multirow{2}{*}{$\begin{array}{l}\text { Number of eligible children } \\
\text { aged } 12-59 \text { months } \\
\text { Mean + SD }\end{array}$} \\
\hline & Number & Percentage & Number & Percentage & Number & Percentage & & \\
\hline \multicolumn{9}{|l|}{ Akkar } \\
\hline Akkar & 390 & 4.2 & 320 & 4.5 & 70 & 3.2 & $5.5+2.7$ & $2.0+1.3$ \\
\hline \multicolumn{9}{|l|}{ Baalbek-Hermel } \\
\hline Baalbek & 390 & 4.2 & 262 & 3.7 & 128 & 5.9 & $5.5+2.3$ & $1.6+0.6$ \\
\hline Hermel & 390 & 4.2 & 297 & 4.2 & 93 & 4.3 & $5.2+2.2$ & $1.7+1.0$ \\
\hline \multicolumn{9}{|l|}{ Beirut } \\
\hline Beirut & 380 & 4.1 & 317 & 4.4 & 63 & 2.9 & $4.7+2.1$ & $1.3+0.5$ \\
\hline \multicolumn{9}{|l|}{ Bekaa } \\
\hline Rashaya & 388 & 4.2 & 319 & 4.5 & 69 & 3.2 & $5.1+1.7$ & $1.3+0.5$ \\
\hline West Bekaa & 383 & 4.1 & 285 & 4.0 & 98 & 4.5 & $5.4+2.3$ & $1.4+0.7$ \\
\hline Zahle & 231 & 2.5 & 174 & 2.4 & 57 & 2.6 & $5.4+1.9$ & $1.7+0.9$ \\
\hline \multicolumn{9}{|l|}{ Mount Lebanon } \\
\hline Aley & 385 & 4.1 & 320 & 4.5 & 65 & 3.0 & $4.6+1.9$ & $1.4+0.7$ \\
\hline Baabda & 380 & 4.1 & 276 & 3.9 & 104 & 4.8 & $4.8+1.7$ & $1.3+0.6$ \\
\hline Chouf & 377 & 4.1 & 321 & 4.5 & 56 & 2.6 & $5.3+2.7$ & $1.6+1.0$ \\
\hline El-Metn & 364 & 3.9 & 277 & 3.9 & 87 & 4.0 & $5.5+2.5$ & $1.5+0.7$ \\
\hline Jbeil & 388 & 4.2 & 304 & 4.3 & 84 & 3.9 & $4.8+2.1$ & $1.6+0.7$ \\
\hline Keserwan & 375 & 4.0 & 294 & 4.1 & 81 & 3.7 & $4.6+2.1$ & $1.4+0.6$ \\
\hline \multicolumn{9}{|l|}{ Nabatieh } \\
\hline Bint Jbeil & 390 & 4.2 & 286 & 4.0 & 104 & 4.8 & $4.5+1.6$ & $1.7+0.9$ \\
\hline Hasbaya & 381 & 4.1 & 267 & 3.7 & 114 & 5.2 & $5.4+2.2$ & $2.3+1.4$ \\
\hline Marjeyoun & 388 & 4.1 & 299 & 4.2 & 89 & 4.1 & $4.3+1.7$ & $1.9+1.1$ \\
\hline Nabatieh $^{\mathrm{a}}$ & - & - & - & - & - & - & - & - \\
\hline \multicolumn{9}{|l|}{ North } \\
\hline Batroun & 381 & 4.1 & 277 & 3.9 & 104 & 4.8 & $5.3+2.0$ & $1.4+0.6$ \\
\hline Bcharre & 384 & 4.1 & 281 & 3.9 & 103 & 4.7 & $4.8+1.5$ & $1.9+0.9$ \\
\hline Koura & 390 & 4.2 & 309 & 4.3 & 81 & 3.7 & $4.9+1.9$ & $1.5+0.7$ \\
\hline Minieh-Donieh & 390 & 4.2 & 287 & 4.0 & 103 & 4.7 & $5.7+2.4$ & $1.6+0.8$ \\
\hline Tripoli & 383 & 4.1 & 308 & 4.3 & 75 & 3.4 & $5.7+2.6$ & $1.7+1.3$ \\
\hline Zgharta & 390 & 4.2 & 353 & 5.0 & 37 & 1.7 & $4.1+1.1$ & $1.2+0.4$ \\
\hline \multicolumn{9}{|l|}{ South } \\
\hline Jezzine & 368 & 4.0 & 251 & 3.5 & 117 & 5.4 & $6.0+2.1$ & $1.7+0.8$ \\
\hline Saida & 322 & 3.5 & 234 & 3.3 & 88 & 4.0 & $6.4+3.1$ & $1.6+0.8$ \\
\hline Sour & 327 & 3.5 & 218 & 3.1 & 109 & 5.0 & $5.8+3.3$ & $1.1+0.8$ \\
\hline Total & 9315 & 100.0 & 7136 & 76.6 & 2179 & 23.4 & $5.2+2.2$ & $1.6+0.9$ \\
\hline
\end{tabular}

${ }^{a}$ Nabatieh was not included

\section{Routine vaccination coverage}

Based on vaccination cards and parental recall, vaccination coverage among children aged 12-59 months was below the targeted 95\%, except for the first doses of pentavalent and polio among Lebanese children (Table 4). Complete vaccination coverage of each vaccine separately revealed the highest coverage for the third dose of Hib (88.1\% [95\% CI: 87.0-89.2] among Lebanese, $78.7 \%$ [95\% CI: 76.2-81.0] among Syrians) and the lowest coverage for the second dose of MCV $(64.2 \%$ [95\% CI: 62.4-66.0] among Lebanese, 50.1\% [95\% CI: 47.1-53.1] among Syrians). Dropout rates ranged from 
Table 3 Key sociodemographic factors (unweighted), Lebanon CES 2016

\begin{tabular}{|c|c|c|c|c|c|c|}
\hline \multirow[t]{2}{*}{ Characteristics } & \multicolumn{2}{|c|}{ Total $(n=9315)$} & \multicolumn{2}{|c|}{ Lebanese $(n=7136)$} & \multicolumn{2}{|c|}{ Syrian $(n=2179)$} \\
\hline & Number & Percentage & Number & Percentage & Number & Percentage \\
\hline \multicolumn{7}{|l|}{ Sex of the child } \\
\hline Male & 5044 & 54.1 & 3851 & 54.0 & 1193 & 54.7 \\
\hline Female & 4271 & 45.9 & 3285 & 46.0 & 986 & 45.3 \\
\hline \multicolumn{7}{|l|}{ Age of the child } \\
\hline $12-23$ months & 2579 & 27.7 & 1928 & 27.0 & 651 & 29.9 \\
\hline 24-35 months & 2265 & 24.3 & 1747 & 24.5 & 518 & 23.8 \\
\hline $36-47$ months & 1920 & 20.6 & 1462 & 20.5 & 458 & 21.0 \\
\hline $48-59$ months & 2551 & 27.4 & 1999 & 28.0 & 552 & 25.3 \\
\hline \multicolumn{7}{|l|}{ Place of residency of the caregiver } \\
\hline Rented house / apartment & 4461 & 47.9 & 2562 & 35.9 & 1899 & 87.2 \\
\hline Owned house / apartment & 4547 & 48.8 & 4420 & 61.9 & 127 & 5.8 \\
\hline Informal settlement & 130 & 1.5 & 40 & 0.6 & 90 & 4.1 \\
\hline Collective shelter & 78 & 0.8 & 37 & 0.5 & 41 & 1.9 \\
\hline Other & 49 & 0.5 & 34 & 0.5 & 15 & 0.7 \\
\hline Refused to answer & 50 & 0.5 & 43 & 0.6 & 7 & 0.3 \\
\hline \multicolumn{7}{|l|}{ Social status of the caregiver } \\
\hline Single & 451 & 4.9 & 327 & 4.6 & 124 & 5.7 \\
\hline Married & 8559 & 91.9 & 6567 & 92.0 & 1992 & 91.3 \\
\hline Divorced & 137 & 1.5 & 103 & 1.4 & 34 & 1.6 \\
\hline Widowed man & 51 & 0.5 & 45 & 0.6 & 6 & 0.3 \\
\hline Widowed woman & 88 & 0.9 & 69 & 1.0 & 19 & 0.9 \\
\hline Refused to answer & 29 & 0.3 & 25 & 0.4 & 4 & 0.2 \\
\hline Age of the caregiver & $30.9+6.7$ & & $31.2+6.7$ & & $29.7+6.7$ & \\
\hline Median & 30.0 & & 30.3 & & 28.9 & \\
\hline \multicolumn{7}{|l|}{ Father's educational status } \\
\hline Doesn't know how to read and write & 605 & 6.5 & 312 & 4.4 & 293 & 13.5 \\
\hline Knows how to read and write & 1412 & 15.2 & 795 & 11.1 & 617 & 28.3 \\
\hline Primary/Complementary level & 1830 & 19.7 & 1319 & 18.5 & 511 & 23.5 \\
\hline Secondary level & 1774 & 19.0 & 1609 & 22.6 & 165 & 7.6 \\
\hline Post school technical level & 1035 & 11.1 & 936 & 13.1 & 99 & 4.5 \\
\hline University level & 2527 & 27.1 & 2054 & 28.8 & 473 & 21.7 \\
\hline Doesn't know/Doesn't remember & 39 & 0.4 & 33 & 0.5 & 6 & 0.3 \\
\hline Refused to answer & 93 & 1.0 & 78 & 1.0 & 15 & 0.6 \\
\hline \multicolumn{7}{|l|}{ Mother's educational status } \\
\hline Doesn't know how to read and write & 695 & 7.5 & 312 & 4.4 & 383 & 17.6 \\
\hline Knows how to read and write & 1099 & 11.8 & 626 & 8.8 & 473 & 21.7 \\
\hline Primary/Complementary level & 2330 & 25.0 & 1550 & 21.7 & 780 & 35.8 \\
\hline Secondary level & 1856 & 19.9 & 1614 & 22.6 & 242 & 11.1 \\
\hline Post school technical level & 1243 & 13.3 & 1033 & 14.5 & 210 & 9.6 \\
\hline University level & 1990 & 21.4 & 1915 & 26.8 & 75 & 3.4 \\
\hline Doesn't know/Doesn't remember & 20 & 0.2 & 14 & 0.2 & 6 & 0.3 \\
\hline Refused to answer & 82 & 0.9 & 72 & 1.0 & 10 & 0.5 \\
\hline
\end{tabular}

Father's employment status 
Table 3 Key sociodemographic factors (unweighted), Lebanon CES 2016 (Continued)

\begin{tabular}{|c|c|c|c|c|c|c|}
\hline \multirow[t]{2}{*}{ Characteristics } & \multicolumn{2}{|c|}{ Total $(n=9315)$} & \multicolumn{2}{|c|}{ Lebanese $(n=7136)$} & \multicolumn{2}{|c|}{ Syrian $(n=2179)$} \\
\hline & Number & Percentage & Number & Percentage & Number & Percentage \\
\hline Full-time employee & 6177 & 66.3 & 5127 & 71.8 & 1050 & 48.2 \\
\hline Part-time employee & 2204 & 23.7 & 1462 & 20.5 & 742 & 34.1 \\
\hline Unemployed & 705 & 7.6 & 348 & 4.9 & 357 & 16.4 \\
\hline Retiree & 48 & 0.5 & 43 & 0.6 & 5 & 0.2 \\
\hline Refused to answer & 181 & 1.9 & 156 & 2.2 & 25 & 1.1 \\
\hline \multicolumn{7}{|c|}{ Mother's employment status } \\
\hline Full-time employee & 2816 & 30.2 & 2344 & 32.8 & 472 & 21.7 \\
\hline Part-time employee & 1772 & 19.0 & 1375 & 19.3 & 397 & 18.2 \\
\hline Unemployed & 4595 & 49.4 & 3302 & 46.3 & 1293 & 59.3 \\
\hline Retiree & 21 & 0.2 & 14 & 0.2 & 7 & 0.3 \\
\hline Refused to answer & 111 & 1.2 & 101 & 1.4 & 10 & 0.5 \\
\hline
\end{tabular}

Table 4 Routine vaccination coverage according to cards or card information and caregivers' recall, Lebanon CES 2016

\begin{tabular}{|c|c|c|c|c|}
\hline \multirow{3}{*}{$\begin{array}{l}\text { Vaccine } \\
\text { Source }\end{array}$} & \multicolumn{2}{|l|}{ Lebanese $(n=7136)$} & \multicolumn{2}{|l|}{ Syrian $(n=2179)$} \\
\hline & Card $(n=4363)$ & Card+Recall $^{\mathrm{a}}(\mathrm{n}=7136)$ & Card $(n=1350)$ & Card+Recall $(n=2179)$ \\
\hline & Percentage $^{b}[95 \% \mathrm{Cl}]$ & Percentage [95\% Cl] & Percentage ${ }^{\mathrm{b}}[95 \% \mathrm{Cl}]$ & Percentage $[95 \% \mathrm{Cl}]$ \\
\hline HepB 0 dose & 86.6 [84.8-88.2] & $85.5[84.0-86.8]$ & $67.0[63.0-70.8]$ & $70.7[67.6-73.6]$ \\
\hline Polio 1st dose & $96.1[95.2-96.8]$ & $95.4[94.6-96.0]$ & $94.5[92.2-96.2]$ & $92.3[90.2-94.0]$ \\
\hline Polio 2nd dose & 91.5 [90.3-92.6] & 91.9 [90.9-92.8] & $84.5[81.3-87.2]$ & $84.7[82.1-87.0]$ \\
\hline Polio 3rd dose & $87.4[86.0-88.7]$ & $87.2[86.0-88.4]$ & $76.5[73.1-79.6]$ & $76.4[73.6-79.0]$ \\
\hline Dropout (Polio 1-Polio 3) & 8.7 & 8.2 & 18.0 & 15.9 \\
\hline DTP 1st dose & 95.9 [95.0-96.6] & $95.9[95.1-96.5]$ & 89.4 [86.7-91.6] & $89.9[87.7-91.7]$ \\
\hline DTP 2nd dose & $92.5[91.4-93.4]$ & $90.1[89.0-91.1]$ & $83.7[80.8-86.2]$ & $82.0[79.7-84.1]$ \\
\hline DTP 3rd dose & $88.8[87.4-90.0]$ & $87.7[86.5-88.9]$ & $76.6[73.5-79.5]$ & $77.5[75.1-79.8]$ \\
\hline Dropout (DTP 1-DTP 3) & 7.1 & 8.2 & 12.8 & 12.4 \\
\hline HepB 1st dose & $95.2[94.2-96.0]$ & $94.9[94.2-95.6]$ & $87.9[85.1-90.2]$ & 89.0 [86.8-90.9] \\
\hline HepB 2nd dose & 91.9 [90.7-92.9] & $89.6[88.5-90.7]$ & $82.2[79.1-84.9]$ & $82.8[80.4-85.0]$ \\
\hline HepB 3rd dose & $84.8[83.1-86.2]$ & $85.1[83.7-86.3]$ & $71.5[68.0-74.8]$ & $76.1[73.3-78.6]$ \\
\hline Dropout (HepB 1-НерB 3) & 10.4 & 9.8 & 16.4 & 12.9 \\
\hline Hib 1st dose & $95.3[94.3-96.2]$ & $94.8[94.1-95.5]$ & $88.4[85.6-90.7]$ & $88.9[86.8-90.8]$ \\
\hline Hib 2nd dose & $92.3[91.2-93.3]$ & $90.5[89.4-91.4]$ & $83.4[80.5-86.1]$ & $83.5[81.1-85.6]$ \\
\hline Hib 3rd dose & 88.7 [87.3-89.9] & $88.1[87.0-89.2]$ & $76.0[72.7-79.0]$ & $78.7[76.2-81.0]$ \\
\hline Dropout (Hib 1-Hib 3) & 6.6 & 6.7 & 12.4 & 10.2 \\
\hline MCV 1st dose & $86.7[85.3-88.0]$ & $83.1[81.7-84.4]$ & $79.3[76.1-82.1]$ & $73.5[70.6-76.3]$ \\
\hline MCV 2nd dose & $64.8[62.7-66.9]$ & $64.2[62.4-66.0]$ & $51.6[48.1-55.1]$ & $50.1[47.1-53.1]$ \\
\hline Dropout (MCV 1-MCV 2) & 21.9 & 18.9 & 27.7 & 23.4 \\
\hline Dropout (DTP 1-MCV 1) & 9.2 & 12.8 & 10.1 & 16.4 \\
\hline RCV 1st dose & $72.4[70.3-74.4]$ & $70.8[69.0-72.6]$ & $69.2[65.4-72.7]$ & $62.1[59.0-65.0]$ \\
\hline
\end{tabular}


6.7\% (Hib 1 - Hib 3) to $18.9 \%$ (MCV 1 - MCV 2) among Lebanese and $10.2 \%$ (Hib 1 - Hib 3) to $23.4 \%$ (MCV 1 - MCV 2) among Syrian children.

\section{Routine vaccination coverage by district}

The coverage of any routinely administered vaccine differed between districts in Lebanon (Fig. 1). The difference in coverage among children aged 12-59 months for the third dose of polio ranged from 61.3\% [95\% CI:
50.9-70.7] in Bcharre to 95.9\% [95\% CI: 93.4-97.4] in Aley among Lebanese and from 45.0\% [95\% CI: 21.647.5] in Jezzine to $90.2 \%$ [95\% CI: 81.5-95.1] in Hasbaya among Syrians. Similar variations were identified for all doses and all types of vaccines. However, the majority of districts presented an immunization level at the upper end of the targeted coverage. It was noted that more than $90.0 \%$ coverage of the first dose of polio was observed in all districts for Lebanese children, with the
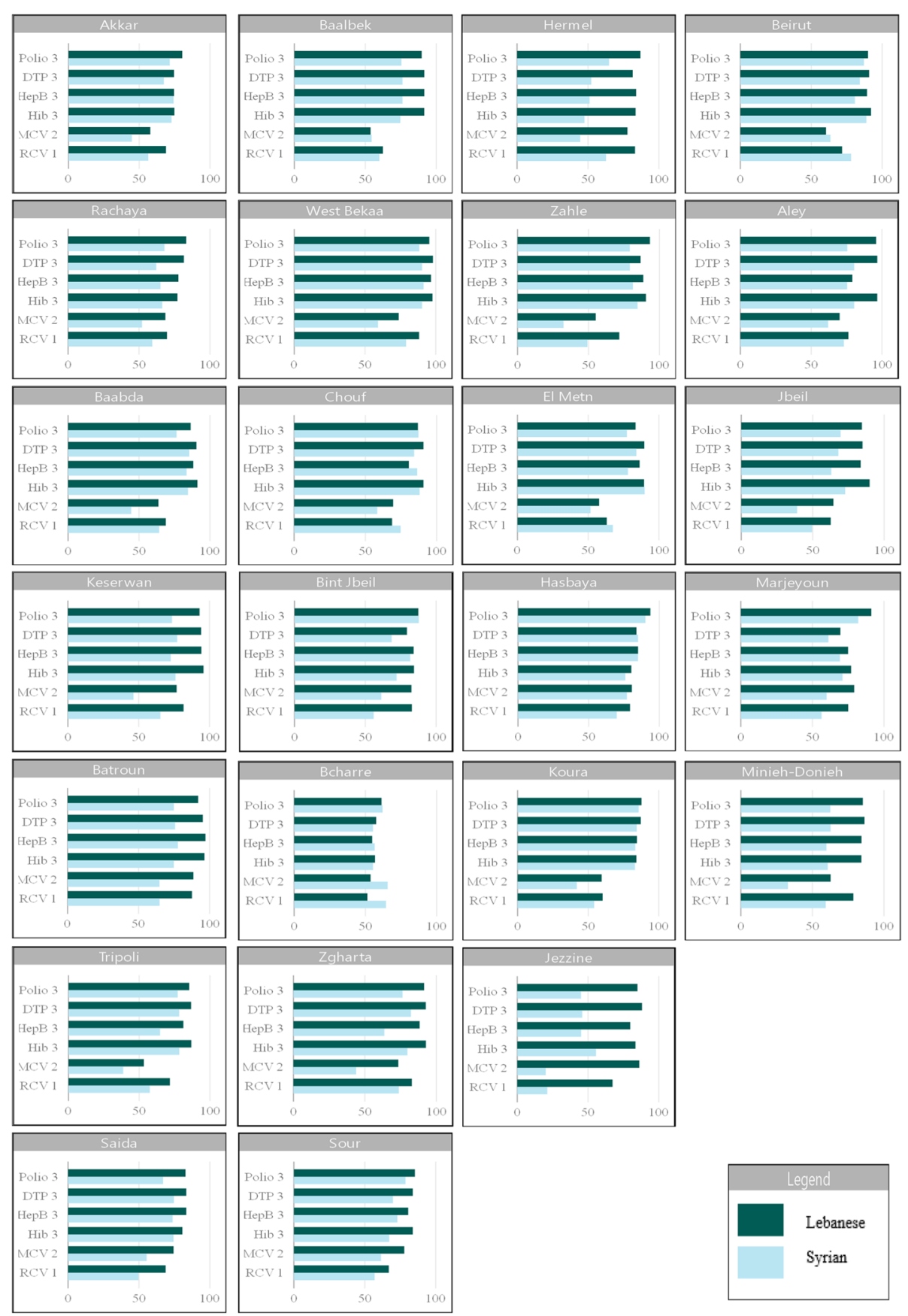

Fig. 1 Routine vaccination coverage at the district level among children aged 12-59 months, Lebanon CES 2016 
exception of Bcharre (78.9\% [95\% CI: 67.1-87.3]). Similarly, Syrians had a coverage of more than $90.0 \%$ in most districts for polio dose one; however, the vaccination coverage was lowest in Sour (87.2\% [95\% CI: 79.7-92.1]), Batroun (83.3\% [95\% CI: 60.1-94.3]), Jezzine (77.0\% [95\% CI: 63.2-86.6]), Rachaya (76.6\% [95\% CI: 63.8-85.9]), and Saida (72.7\% [95\% CI: 55.9-84.9]). The earlier ascertained disparity in coverage between Lebanese and Syrians changed when rates were analyzed at the district level. While overall coverage was generally higher among Lebanese than Syrians in Lebanon, large variations were revealed when focusing on various geographical areas.

\section{Factors associated with completed vaccination}

As shown in Table 5, nationality was significantly associated with all types of vaccines except RCV, with Lebanese having significantly higher odds for completing vaccine coverage compared to Syrians, adjusting for other variables in the analysis. The child's sex was not a significant predictor of vaccination coverage. The odds of having completed vaccination for all routine vaccinations increased with age. Children who received vaccinations at a private clinic were more likely to reach complete coverage for all types of vaccines, with the exception of polio and MCV. Mothers' educational status significantly increased the odds for a child to be vaccinated, with mothers who completed their primary level of education or higher having higher odds of having a vaccinated child compared to illiterate mothers. This association was significant for all types of vaccines excluding HepB.

\section{Reasons for Undervaccination}

The child being sick at the time for administering the vaccine was one of the main justifications for undervaccination of any kind of vaccine $(3.1 \%$ for Hib up to $33.3 \%$ for MCV). Other common explanations were the inability to pay the fees for vaccination ( $4.7 \%$ for IPV up to $17.5 \%$ for Hib), lack of awareness of the need for immunization (4.4\% for MCV up to $15.5 \%$ for OPV) or the vaccine's importance $(2.1 \%$ for RCV up to $6.4 \%$ for OPV). In many other cases, caregivers stated that the doctor did not advise vaccinating the child, which was most commonly reported for IPV (17.5\%) and НерB (10.8\%). Administration of Hib was often denied because parents did not trust the quality of the vaccine (18.4\%). Other common reasons for undervaccination were the lack of availability of the vaccine, the child's age or the reluctance of the parents to vaccinate their child. These reasons were not significantly different for Lebanese versus Syrian children for all types of vaccines.

\section{Discussion}

Despite tremendous efforts to optimize immunization coverage, major challenges to reaching every child with needed protection against preventable diseases in Lebanon persist. National estimates of vaccine coverage do not detect gaps that are only revealed when looking at the district level. This study highlights substantial variability in vaccination coverage among children aged 12-59 months residing in different districts. While some areas present coverage rates up to almost $100 \%$, others indicate inadequacies in the provision of vaccination services with coverage rates as low as $20.1 \%$. According to the routine vaccination schedule of the $\mathrm{MoPH}$, at the age of 12 months, a child should have received at least three doses of polio vaccine, DTP, and Hib, four doses of HepB vaccine and at least one dose of MCV [2]. The findings show, however, that routine vaccination coverage falls below levels that provide sufficient population immunity to prevent outbreaks [13]. Immunization coverage reaches 95\% or above only for the first doses of pentavalent and polio among Lebanese children. Moreover, dropout rates higher than the $10.0 \%$ cutoff point set by the WHO were noted for all vaccines administered to Syrian children and for MCV among Lebanese children [10]. These dropouts are indicative of delayed follow-up or missed opportunities to administer vaccines on time.

Insufficient or missing vaccination coverage may result from multiple causes, including immunization system weaknesses, children's family characteristics and parental attitudes or knowledge $[14,15]$. In line with previously conducted research in Lebanon, this study shows discrepancies in the vaccination coverage for Lebanese and Syrian children [8]. These discrepancies, with large variations at the district level, suggest gaps in targeting vulnerable children. A series of vaccination campaigns and other vaccination initiatives in 2014, 2015 and 2016 following the influx of Syrians into Lebanon was established, which achieved adequate coverage levels for polio and measles [1]. Nevertheless, the study results highlight the importance of continuing vaccination efforts and extending initiatives to those children left behind in previous campaigns, particularly refugee and vulnerable children living in host communities. The additional challenges to the Lebanese healthcare system in recent years have stretched services and public infrastructure to the maximum to cope with the unprecedented increase in demand for vaccines [16].

In addition to the discrepancy in vaccination coverage associated with the child's nationality, the results from this study suggest a difference in vaccine administration compliance between public and private providers. In Lebanon, children can receive vaccinations at public or private facilities [1]. The vaccine market is well established, and different types of vaccines are available. However, this privilege is mostly reserved for those receiving their vaccinations at private clinics, which administer types of vaccines that are often different from 


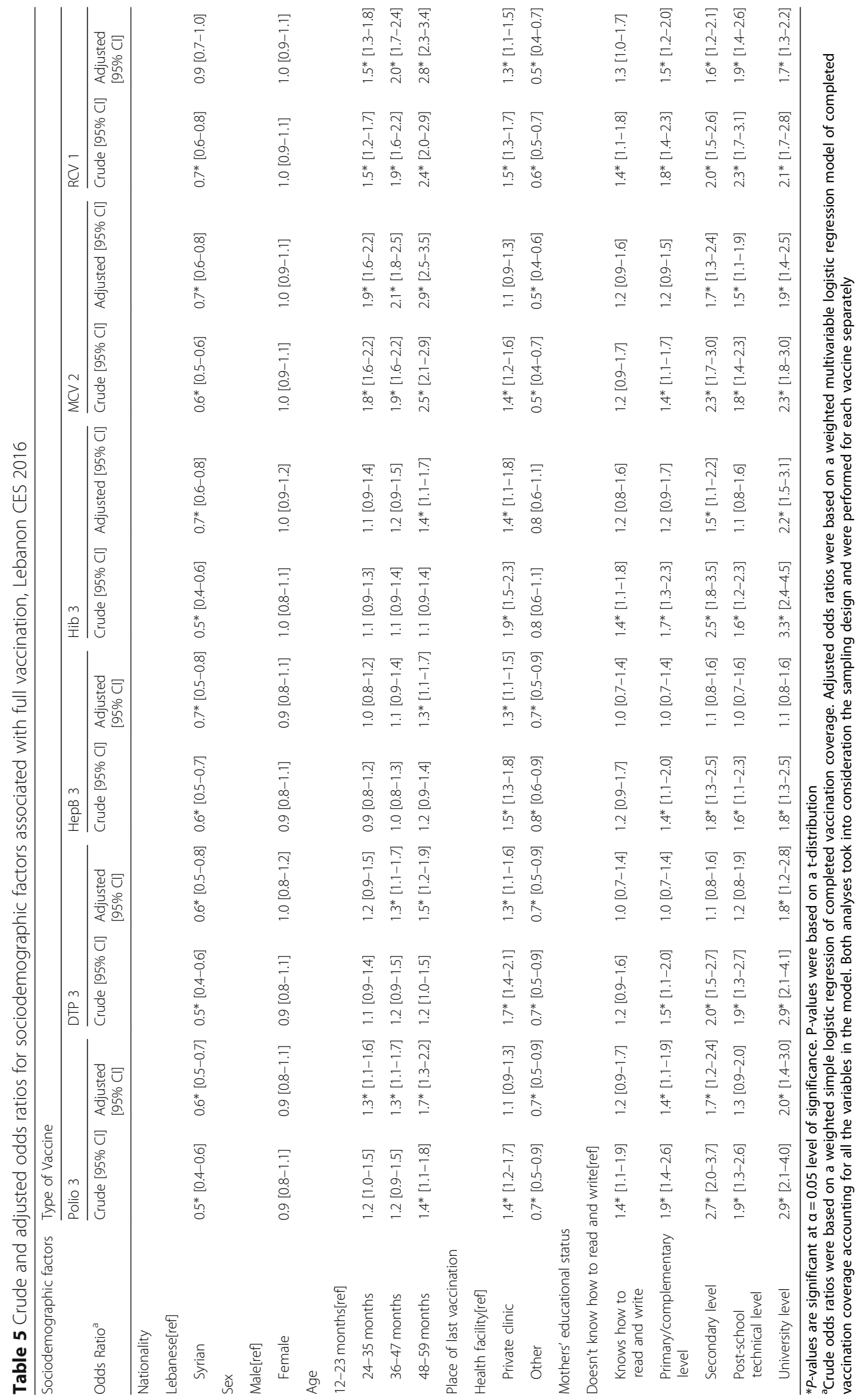


those provided by public healthcare facilities due to contractual and financial circumstances. The diverse forms of vaccinations received create difficulties in tracking where a child received the vaccination and create obstacles to assessing vaccination coverage and its completeness. Good record keeping for vaccination cards is, therefore, fundamental to reducing sources of error [17-19]. It is critical to comply with the recommended schedule to optimize protection from preventable diseases.

In addition to immunization system characteristics and the children's background, mothers' education was identified as impacting a child's complete vaccination status; the reasons caregivers provided for undervaccination included parental unawareness, attitude or inability to pay vaccination fees to healthcare providers' practices or lack of availability of the vaccine. This complexity suggests that additional efforts are needed to ensure complete vaccination for children residing in Lebanon. Adherence to the national routine vaccination schedule requires not only affordable and available vaccines but also persuasion of providers and caregivers that complete vaccination is of the utmost importance to protect a child's health. Misperceptions seem to exist with regard to immunization and its administration indicated by many children missing their vaccination due to illness, although a mild infection should not prevent a child from receiving immunization [20].

The study results should be considered in light of potential limitations. Although the EPI methodology, which is a validated and highly recommended vaccination coverage cluster survey method, was applied, the approach was limited by the use of an old sampling frame and the lack of an existing household listing, compelling the researchers to rely on other available population estimates. Instead of using the global positioning system, fieldworkers relied on local authorities to define cluster boundaries and to choose landmarks in each area to locate study participants. Nonetheless, household surveys may be more reliable if they are well-conducted and measure vaccination coverage using different means, with each having its advantages and disadvantages [18]. In household surveys, the accuracy of the data is also dependent on the available vaccination documentation. In this study, both vaccination cards and recall of caregivers were used as sources for vaccination coverage. The lack of availability of cards and misplaced cards impeded operations; therefore, the verbal history provided by caregivers was taken into account. However, relying on recall is increasingly associated with incomplete or inaccurate vaccination documentation, and even vaccination cards may maintain low quality records of a child's immunization status [19]. Nevertheless, the strengths of this study were the high response rate and the use of 5713 pictures of cards, which allowed better ascertainment of vaccination status despite the multiple types of vaccines used in Lebanon.

\section{Conclusions}

The study findings suggest considerable variability in routine vaccination coverage in Lebanon. Obstacles to reaching every child in need of vaccination remain. High dropout rates suggest that many children remain susceptible to vaccine preventable diseases, particularly Syrian children. Optimizing coverage levels will require vaccination initiatives targeting both refugee children and children from vulnerable host communities, increased cooperation between public and private vaccine providers, training for vaccine providers to adhere to complete vaccine administration and increased awareness among caregivers.

\section{Additional file}

Additional file 1: Expanded Programme of Immunization Cluster Survey 2015. Survey questionnaire. (DOCX $195 \mathrm{~kb}$ )

\begin{abstract}
Abbreviations
CES: Coverage evaluation survey; Cl: Confidence interval; DTP: Diphtheria, tetanus, pertussis; EPI: Expanded Programme on Immunization; HepB: Hepatitis B; Hib: Haemophilus influenzae type b; IPV: Inactivated polio vaccine; MCV: Measles-containing vaccine; MMR: Measles, mumps, rubella; MoPH: Ministry of Public Health; OPV: Oral polio vaccine; RCV: Rubellacontaining vaccine; UNICEF: United Nations Children's Fund; WHO: World Health Organization
\end{abstract}

\section{Acknowledgements}

The authors acknowledge the support of the Lebanese Ministry of Public Health, the World Health Organization, the Lebanese Pediatric Society, and the United Nations Children's Fund. The research team thanks the communities that were surveyed.

\section{Funding}

This study would not have been possible without the financial support of the Bill \& Melinda Gates Foundation through the World Health Organization. The funders had no role in study design, data collection and analysis, decision to publish, or preparation of the manuscript.

Availability of data and materials

The datasets generated during the current study are not publicly available owing to data protection concerns but are available from the corresponding author at saidr@crdconsultancy.org on reasonable request.

\section{Authors' contributions \\ All persons who meet authorship criteria are listed as authors, and all authors certify that they have participated sufficiently in the work to take public responsibility for the content, including participation in the concept, design, analysis, writing, or revision of the manuscript. Authors $Z M, R H, A R$, MCD, KF, RS, LB, RW and WA contributed to the conception and design of the study. In addition, ZM contributed to the data interpretation; RS contributed to the data acquisition, data analyses and interpretation; LB contributed to the data analyses and interpretation; RW contributed to the data analyses. All authors provided input into drafts, read and approved the final manuscript.}

Ethics approval and consent to participate

Ethical approval was obtained from the Institutional Review Board at Sagesse University to conduct the research as per the reference number IRB120416B, 
and oral informed consent was obtained from the participants. The use of oral consent was approved by the Institutional Review Board.

\section{Consent for publication}

Not applicable.

\section{Competing interests}

The authors declare that they have no competing interests.

\section{Publisher's Note}

Springer Nature remains neutral with regard to jurisdictional claims in published maps and institutional affiliations.

\section{Author details}

${ }^{1}$ Connecting Research to Development, Beirut, Lebanon. ${ }^{2}$ Ministry of Public Health, Beirut, Lebanon. ${ }^{3}$ World Health Organization Lebanon Country Office, Beirut, Lebanon. ${ }^{4}$ World Health Organization, Geneva, Switzerland. ${ }^{5}$ World Health Organization Eastern Mediterranean Region Office, Cairo, Egypt.

Received: 30 July 2018 Accepted: 9 January 2019

Published online: 14 January 2019

\section{References}

1. Ministry of Public Health. Expanded program on immunization. 2017. http:// www.moph.gov.lb/en/Pages/3/1033/expanded-program-on-immunization. Accessed 30 Jun 2017

2. Ministry of Public Health. National immunization calendar. 2017. http:// www.moph.gov.lb/en/Pages/3/1033/expanded-program-on-immunization\#/ en/DynamicPages/view/4452/national-immunization-calendar. Accessed 30 Jun 2017.

3. Ministry of Public Health. Conflict reduction through improving healthcare services for the vulnerable population in Lebanon. 2015. http://www.moph. gov.lb/en/Pages/6/2918/eu-ifs-project. Accessed 30 Jun 2017.

4. World Health Organization. WHO vaccine-preventable diseases: monitoring system. 2016 global summary. 2016. http://apps.who.int/immunization_ monitoring/globalsummary/ countries?countrycriteria\%5Bcountry\%5D\%5B\%5D=LBN\&commit=OK. Accessed 30 Jun 2017.

5. United Nations Children's Fund. UNICEF in Lebanon and Immunization Campaigns. Hum Heal. 2017:12-5.

6. Sharara SL, Kanj SS. War and infectious diseases: challenges of the Syrian civil war. PLoS Pathog. 2014;10:e1004438.

7. World Food Program, United Nations High Commissioner for Refugees, United Nations Children's fund. Vulnerability assessment of Syrian refugees in Lebanon. 2015. https://reliefweb.int/sites/reliefweb.int/files/resources/ 2015VASyR.pdf. Accessed 30 Jun 2017.

8. Rossi R, Assaad R, Rebeschini A, Hamadeh R. Vaccination coverage cluster surveys in middle Dreib - Akkar, Lebanon: comparison of vaccination coverage in children aged 12-59 months pre- and post-vaccination campaign. PLoS One. 2016:e0168145.

9. Ministry of Public Health, World Health Organization. Expanded Programme on Immunization - District-Based Immunization Coverage Cluster Survey. Beirut; 2016. https://data2.unhcr.org/fr/documents/download/63859. Accessed 18 Oct 2018

10. World Health Organization. Vaccination coverage cluster surveys - reference manual. Geneva: World Health Organization; 2015.

11. Central Administration of Statistics. Population characteristics in 2009. 2009. http://www.cas.gov.lb/index.php/demographic-and-social-en/population-en. Accessed 30 Jun 2017.

12. United Nations High Commissioner for Refugees. Syria regional refugee response. 2014. http://data.unhcr.org/syrianrefugees/country.php?id=122. Accessed 30 Jun 2017.

13. Vynnycky E, White R. An Introduction to Infectious Disease Modelling. Oxford: Oxford University Press; 2010.

14. Rainey JJ, Watkins M, Ryman TK, Sandhu P, Bo A, Banerjee K. Reasons related to non-vaccination and under-vaccination of children in low and middle income countries: findings from a systematic review of the published literature, 1999-2009. Vaccine. 2011;29:8215-21.

15. Sridhar S, Maleq N, Guillermet E, Colombini A, Gessner BD. A systematic literature review of missed opportunities for immunization in low- and middle-income countries. Vaccine. 2014;32:6870-9.
16. Ammar W, Kdouh O, Hammoud R, Hamadeh R, Harb H, Ammar Z, et al. Health system resilience. Lebanon and the Syrian refugee crisis. J Glob Health. 2016;6:e020704.

17. Travassos MA, Beyene B, Adam Z, Campbell JD, Mulholland N, Diarra SS, et al. Immunization coverage surveys and linked biomarker serosurveys in three regions in Ethiopia. PLoS One. 2016;11:e0149970.

18. Cutts FT, Claquin P, Danovaro-Holliday MC, Rhoda DA. Monitoring vaccination coverage: defining the role of surveys. Vaccine. 2016;34:4103-9.

19. Miles M, Ryman TK, Dietz V, Zell E, Luman ET. Validity of vaccination cards and parental recall to estimate vaccination coverage: a systematic review of the literature. Vaccine. 2013:31:1560-8.

20. World Health Organization. Measles vaccines: WHO position paper - April 2017. Wkly Epidemiol Rec. 2017;92:205-27.
Ready to submit your research? Choose BMC and benefit from:

- fast, convenient online submission

- thorough peer review by experienced researchers in your field

- rapid publication on acceptance

- support for research data, including large and complex data types

- gold Open Access which fosters wider collaboration and increased citations

- maximum visibility for your research: over $100 \mathrm{M}$ website views per year

At $\mathrm{BMC}$, research is always in progress.

Learn more biomedcentral.com/submissions 